\title{
Hanging on the line - on the need to assess the risk to global submarine telecommunications infrastructure - an example of the Hawaiian "bottleneck" and Australia
}

\author{
D. Dominey-Howes and J. Goff \\ Australian Tsunami Research Centre, University of New South Wales, Sydney, NSW 2052, Australia \\ Received: 21 January 2009 - Revised: 19 March 2009 - Accepted: 22 March 2009 - Published: 17 April 2009
}

\begin{abstract}
National economies are becoming increasingly dependent on the global telecommunications system - and in particular, its submarine cable infrastructure. We note that a variety of natural hazard processes are capable of damaging and destroying this infrastructure, both in deep water and at the coast. Some places within the global telecommunications system are already known to be bottlenecks or "choke points". Hawaii is just such a choke point and interestingly, Hawaii is also affected by numerous large magnitude natural hazard processes. Any damage to the submarine telecommunications infrastructure routed through Hawaii could result in significant impacts on the electronic flow of data and voice traffic, negatively affecting dependent economies such as Australia. We propose that proper risk assessments be undertaken at all bottlenecks in the global telecommunications system affected by natural hazards (such as tsunami). We use Hawaii as an example of the sort of research that should be undertaken.
\end{abstract}

\section{Introduction}

In the highly connected world of the 21 st century, the "global" economy is dependent on high-speed telecommunications traffic and its associated infrastructure (Fig. 1A). This critical telecommunications infrastructure supports electronic ("e"- for short) commerce and business, communications, and knowledge and information exchange. For example, fibre optic cables carry approximately $99 \%$ of Australia's annual international voice and data traffic worth tens billions AUS\$ to the annual e-Economy (Walker, 2008). Australia

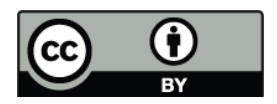

Correspondence to: D. Dominey-Howes (dale.dh@unsw.edu.au) is becoming increasingly reliant upon submarine cables and in fact, Australia's use of international bandwidth has tripled since 2004 (Australian Federal Government, 2009). Any disruption or damage to major submarine cables can have serious consequences by dramatically reducing the flow of information between users. A sustained outage would cause data loss, significant delay and severe financial loss not only to cable owners but also to users relying on communication with the rest of the world.

It is well understood that submarine cables are vulnerable to damage and breakage due to human activity such as fishing, trawling and dredging in shallow water (International Cable Protection Committee, 2006). However, natural hazards such as tsunami, earthquakes and submarine sediment slides are by far the most significant threat in waters deeper than $1000 \mathrm{~m}$ (International Cable Protection Committee, 2006). Cables may be broken in deep water by earthquakes that cause vertical ruptures of the seafloor. Earthquakes may also trigger submarine sediment slides that may physically break the cables (e.g. Puerto Rico, 1918; Horbach et al., 2008). Tsunami can damage or break submarine cables in deep water by triggering sediment slumps. Just as likely however, tsunami can damage cables in shallow water adjacent to the coast where they come onshore because of very fast flowing currents that exceed the shear capacity of the cables. Further, tsunami may physically damage onshore infrastructure where the cables connect to their terrestrial based elements. High sediment load in shallow water tsunami flow may also damage cables. Finally, extreme weather events such as storms and tropical cyclones and volcanic eruption's all have the potential to damage submarine cables and their associated infrastructure.

The December 2006 Taiwan earthquake cut submarine cables, interrupting telecommunication traffic throughout SE Asia and Australasia for approximately two months

Published by Copernicus Publications on behalf of the European Geosciences Union. 

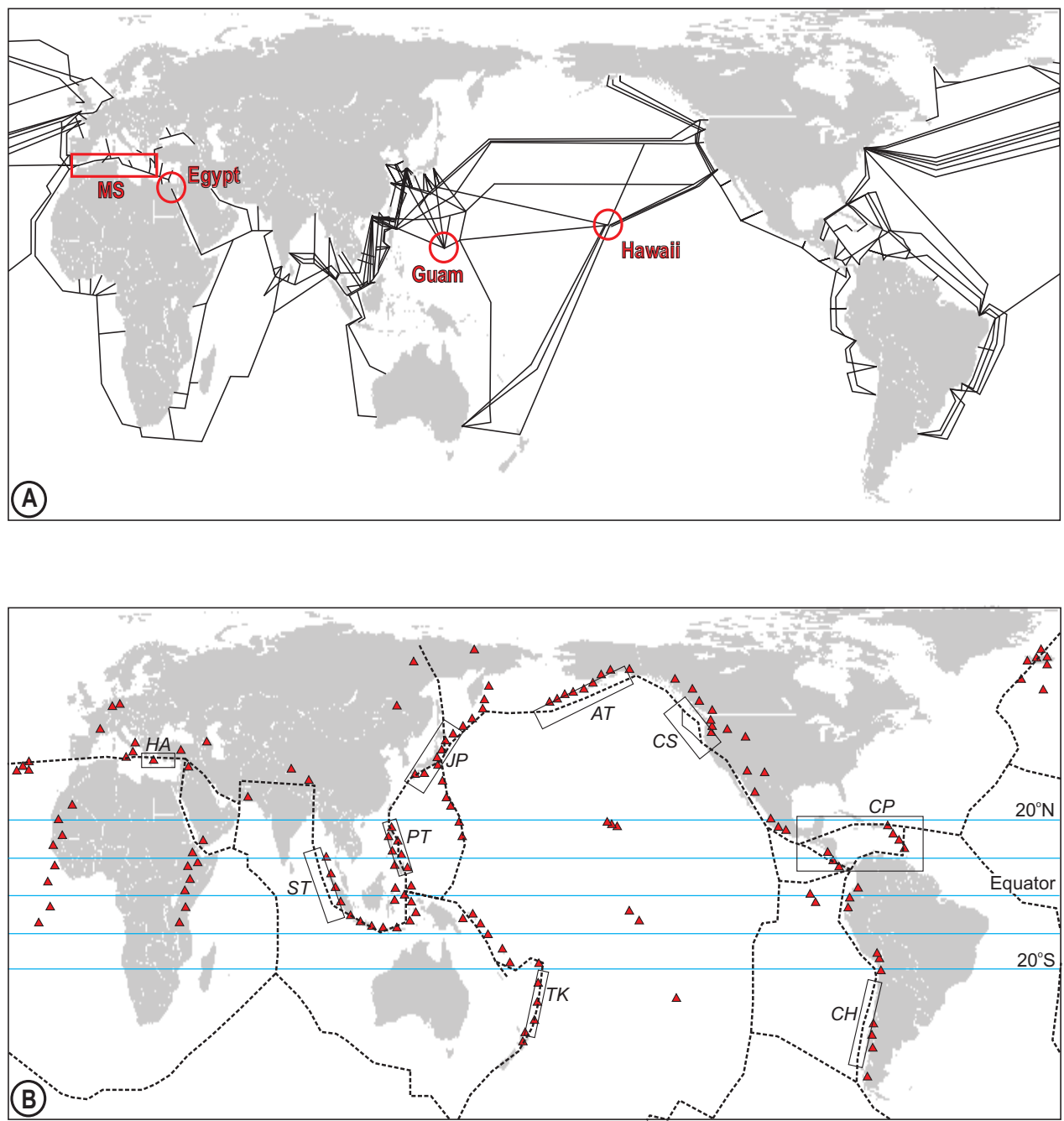

Fig. 1. World maps: (A) Approximate location of submarine telecommunication cables (after www.telegeography.com), (B) Summary of main plate boundaries (dashed lines), approximate cyclone/hurricane zone (blue lines) and locations of volcanic regions (red triangles). Important tectonic subduction zones where earthquakes occur and tsunami are triggered include: HA - Hellenic Arc, ST - Sunda Trench, TK - Tonga-Kermadec Trench, PT - Philippines Trench, JP - Japan Plate Boundary, AT - Aleutian Trench, CS - Cascadia Subduction Zone, $\mathrm{CH}$ - Chilean Subduction Zone, CP - Caribbean Plate.

(LaPerrière, 2007; Rosenberg, 2008). Although electronic traffic in and out of Australia was slowed, it did not completely cease because over $70 \%$ of all Australian daily traffic volume is actually routed via cables that pass through Hawaii (ACMA, 2006) (Fig. 1A).

Whilst numerous hazard processes can damage submarine telecommunications cables in many different parts of the world, in the remainder of this short communication, we explore the risk to submarine cables from tsunami in the region of Hawaii and use this case as an example to outline a series of important research questions that remain to be addressed.

\section{Hawaii - a telecommunications "bottleneck"}

Hawaii is an internationally recognised bottleneck or "choke point" in the global telecommunications network. This is because of the enormous volume of electronic traffic passing through a relatively small number of cables (Svensson, 2008) (Fig. 1A). Clearly, any damage to the fibre optic cables that pass through Hawaii resulting in interruptions to data flow would represent a major threat to the [global] eEconomy. The longer the interruption - the greater the consequence would be for any economies dependent upon the flow of traffic via that location (Rosenberg, 2008; Svensson, 2008). As already noted, following the Taiwan earthquake, most international traffic in to and out of Australia was routed via Hawaii. 
Hawaii is a major natural hazards hotspot extremely vulnerable to the impact of local, regional and trans-Pacific tsunami generated at various locations around the Pacific (Fig. 1B). Hawaii was severely impacted by tsunami in 1975, 1964, 1960, 1957, 1952, and 1946 (Dudley and Lee, 1998). These events all occurred before the submarine cables that currently serve Australia were laid. Significantly, Hawaii's historic tsunami record only extends back as far as AD1811, and its palaeotsunami record is almost nonexistent (Dudley and Lee, 1998). Consequently, we have little idea of the threat to Australia's critical telecommunications infrastructure from tsunami and tsunami-related hazards (e.g., earthquakes, submarine sediment slides and volcanic eruptions) that will affect the Hawaiian bottleneck in the future. We need to understand and assess the "record" of past events better in order to begin to be able to evaluate the risk to our critical submarine telecommunications infrastructure. Fortunately, given Hawaii's geographic location at the centre of the Pacific, it is a natural laboratory capable of preserving evidence of past events that have affected the entire Pacific basin.

Given the importance of submarine cables to Australia's E-economy, we suggest that two important research questions remain to be answered - namely; how often do tsunami impact Hawaii and how big can they be? In order to address these questions however, we must be able to identify and date the geological records of modern and palaeotsunami in Hawaii (Goff et al., 2006). Geological records of palaeotsunami are extremely valuable because they can be used to estimate recurrence intervals of tsunami and their source events, including earthquakes, landslides, or volcanic eruptions, and to model source processes on meaningful timescales of $10^{1}$ to $10^{6}$ years (Dominey-Howes, 2007; Goff, 2008).

Unfortunately, estimates of tsunami magnitude and frequency for Hawaii are currently based upon a mere 200year record of historic events. A longer-term palaeotsunami record for Hawaii would therefore provide the opportunity to more realistically evaluate recurrence intervals and assess the probability of future events. This is exactly the sort of data required to underpin a robust assessment of the risk posed by tsunami and their related hazards to critical submarine telecommunications infrastructure located at the Hawaiian bottleneck. Once such assessments have been completed, appropriate risk management strategies may be developed and applied.

Whilst our discussion has focused on Hawaii, there are other known bottlenecks or "choke points" in the global submarine telecommunications infrastructure such as in the Mediterranean Sea, Egypt, India and Guam (Svensson, 2008). Figure 1B shows that some of these are in locations where natural hazard processes are common and may be very large - e.g., earthquakes at the Cascadia margin and Hellenic Arc, volcanic eruptions in Indonesia, and hurricanes in the Caribbean. Therefore, we recommend that organisations, companies and national governments with an interest in maintaining the global telecommunications network consider the need for risk assessment of their critical infrastructure in those places identified above. Such work will help to ensure that national economies (such as Australia's) are not left "hanging on the line".

Edited by: S. Tinti

Reviewed by: J. Schmidt and another anonymous referee

\section{References}

ACMA: Submarine Cable Protection, Media Release, 2 pp., 24 May 2006.

Australian Federal Government: http://www.ag.gov.au/www/agd/ agd.nsf/Page/Nationalsecurity_CriticalInfrastructureProtection, 2009.

Dominey-Howes, D.: Geological and historical records of tsunami in Australia, Mar. Geol., 239, 99-123, 2007.

Dudley, W. C. and Lee, M.: Tsunami. University of Hawaii Press, Honolulu, 362 pp., 1998.

Goff, J. R.: The New Zealand Palaeotsunami Database. NIWA Technical Report 131, ISSN 1174-2631, 24 pp. + Appendix, 2008.

Goff, J. R., Dudley, W. C., deMaintenon, M., Cain, G., and Coney, J. P.: The largest local tsunami in 20th century Hawaii, Mar. Geol., 226, 65-79, 2006.

Hornbach, M. J., Mondziel, S. A., Grindlay, N. R., Frohlich, C., and Mann, P.: Did a submarine slide trigger the 1918 puerto rico tsunami?, Science of Tsunami Hazards, 27(2), 22-31, 2008.

International Cable Protection Committee: About Submarine Telecommunications Cables: Communicating via the ocean, www.iscpc.org, 46 pp., 2006.

LaPerrière, S.: Taiwan Earthquake Fiber Cuts: a Service Provider View. Abstract. North American Network Operators' Group Annual Conference (NANOG 39), Toronto, 4-9 February 2007.

Rosenberg, M.: India struggling to cope with Internet outages, http: //www.msnbc.msn.com/id/22932251/, 2008.

Svensson, P.: Finger-thin undersea cables tie world together, http: //www.msnbc.msn.com/id/22938899/, 2008.

Walker, M.: Cable failures, http://www.telecomasia.net/article.php? type $=$ article\&id_article $=7138,2008$. 